\title{
TÉCNICA AUXILIAR NA ESFOLIAÇÃO DE DENTES DECÍDUOS EM CRIANÇAS COM MEDO E ANSIEDADE \\ - relato de casos
}

\author{
Rise C. luata Costa Rank*, Joana Estela Rezende Vilela**, Kelry Raianny da S Aguiar***, \\ Omar Franklin Molina**** \\ Autor correspondente: Rise Consolação luata Costa Rank - riserank@yahoo.com.br \\ * Doutora em Odontopediatria. Professora Titular da disciplina de Odontopediatria do Centro Universitário UnirG, Gurupi, \\ TO, Brasil \\ ** Especialista em Saúde Pública. Professora Adjunta na disciplina de Odontopediatria e Saúde Pública do Curso de \\ Odontologia do Centro Universitário UnirG, Gurupi, TO, Brasil \\ *** Graduada em Odontologia pelo Centro Universitário UnirG, Gurupi, TO, Brasil \\ **** Pós-Doutor em Dor Orofacial pela New York University e Harvard University, Professor Titular e Pesquisador Senior do \\ Centro Universitário Unirg, Gurupi, TO, Brasil
}

\section{Resumo}

Introdução: A esfoliação de dentes decíduos é um processo natural acompanhado da reabsorção radicular fisiológica mediada por diversos mecanismos celulares e moleculares, criando assim uma via de irrupção para o sucessor permanente e consequentemente, proporcionando uma oclusão adequada. A exodontia de dentes decíduos é considerada um dos principais procedimentos causadores de medo e ansiedade nas crianças no que se refere a tratamentos odontológicos. Objetivo: Este estudo apresenta a aplicação de uma técnica auxiliar na aceleração da esfoliação de dentes decíduos anteriores em crianças ansiosas e medrosas. Descrição dos casos: As crianças de 6 anos submetidas a procedimento cirúrgico com uso de anestésico local e fórceps, apresentavam medo e ansiedade para remoção dos dentes decíduos em esfoliação, que apesar da mobilidade avançada e reabsorção fisiológica de mais de $2 / 3$ da raiz, não permitiam a remoção dos elementos pelos responsáveis e resistiam ao procedimento de intervenção. As crianças demonstraram aceitação e satisfação pela técnica, pois os dentes decíduos esfoliaram em dois dias sem dor. Conclusão: A técnica auxiliar apresentada demonstrou ser uma alternativa para evitar traumas psicológicos em crianças ansiosas e medrosas. No entanto, tornam-se necessários estudos e pesquisas para melhor avaliar esta técnica.

Palavras-chave: Esfoliação de Dente; Medo; Ansiedade; Odontopediatria. 


\title{
A COMPLEMENTARY TECHNIQUE IN THE SHEDDING OF DECIDUOUS TEETH FOR CHILDREN WITH FEAR AND ANXIETY
}

- cases report •

\begin{abstract}
Introduction: Shedding of deciduous teeth is a natural process occurring together with physiologic resorption via a diversity of molecular and cellular mechanisms, thus, generating an eruption pathway for the permanent tooth and consequently, promoting a physiologic occlusion. Extraction of deciduous teeth, is now considered a major procedure causing fear and anxiety in children during dental treatment. Goal: The aim of this study was to present a complementary technique to accelerate shedding of deciduous teeth. Clinical cases: Description of two clinical cases in two children who demonstrated intense fear associated with the extraction of deciduous teeth presented with mobility and physiologic resorption in $2 / 3$ of the root. The children have accepted the technique application because the deciduous teeth have painlessly fallen out with in two days. Conclusion: The presented aid technique proved to be an alternative to reduce psychological trauma in anxious and fearful's children. However, additional studies and research are required to further assess and evaluate this technique.
\end{abstract}

Keywords: Tooth Exfoliation; Fear; Anxiety; Pediatric Dentistry.

\section{INTRODUÇÃO}

A reabsorção fisiológica do dente decíduo é um fator natural que antecede a irrupção dos dentes permanentes. ${ }^{(1)}$ Lourenço e Consolaro ${ }^{(2)}$ afirmam que o início da reabsorção fisiológica até a esfoliação de dentes decíduos ocorre por volta de 3-6 anos de idade. Vários autores relatam que o exato mecanismo de irrupção dentária ainda é obscuro. Devido a esta complexidade, muitas teorias têm sido propostas para explicar o mecanismo da movimentação do dente no processo irruptivo. ${ }^{(3,4)}$

A reabsorção fisiológica dos elementos decíduos é ativada assim que estes estão completamente formados, com perda da extensão radicular e das estruturas adjacentes. A esfoliação natural pode começar aos 4 anos de idade ou por volta de 1 ano após a formação do dente decíduo, sendo os incisivos centrais os primeiros a sofrerem reabsorção, acompanhados dos incisivos laterais, primeiros molares, segundo molares e caninos. (5) $^{2}$

A reabsorção dos dentes primários cria uma via de irrupção para seu sucessor, proporcionando uma oclusão adequada aos dentes permanentes. A pressão exercida pela irrupção dos permanentes, instiga-se a esfoliação dos decíduos por meio dos odontoclastos, desencadeando o processo fisiológico de reabsorção, tendo como efeito a rizólise. ${ }^{(6)}$

O processo de reabsorção dentária fisiológica em dentes decíduos inicia-se com a apoptose dos cementoblastos e odontoblastos que revestem a parte externa e interna das raízes dentárias. Este processo de apoptose ocorre em células isoladas, com alterações nucleares como a condensação da cromatina, fragmentação do DNA e rompimento do núcleo, a célula perde líquido, encolhe-se e rompe o contato com as outras células dando origem a cor- 
pos apoptóticos que são fagocitados pelos macrófagos. Logo após instalam-se os odontoblastos na superfície da raíz dentária que liberam enzimas que solubilizam a matriz mineral. Este mecanismo programado funciona como gatilho para a rizólise. ${ }^{(7)}$

Mediadores químicos como a prostaglandina, fatores de crescimento epidérmico, a interleucina 1 (IL-1) e a proteína morfogenética óssea estão presentes no folículo pericoronário do germe dental permanente e determina o seu papel na reabsorção fisiológica. ${ }^{(2)}$

Durante a reabsorção radicular do dente decíduo, o osso presente entre o germe do dente sucessor e a raiz do antecessor é reabsorvido. Posteriormente, os cementoclastos, que são células de reabsorção se colocam próximo ao ápice radicular do decíduo e começam a reabsorver o cemento. Essa reabsorção na superfície forma cavidades chamadas "lacunas de Howship". Em seguida, inicia-se a reabsorção da dentina, causada pelas células dentinoclastos. Os cementoblastos e osteoblastos depositam osso e cemento nas áreas reabsorvidas. Ocorre reorganização das fibras do periodonto e, após um período de repouso, inicia-se outra vez a fase ativa de reabsorção. A reabsorção nos dentes unirradiculares inicia pela lingual, continuando pela face vestibular, e seguindo de modo transversal ao longo eixo do dente. ${ }^{(8)}$

Os sinais clínicos de um elemento dental decíduo com reabsorção fisiológica de mais de dois terços é a mobilidade dental grau 2 a 3 e a sintomatologia é mínima. Já, a reabsorção patológica causada por traumas ou infecções, em geral vem acompanhada de sintomatologia dolorosa, pode evidenciar edema na região periodontal.(4)

A retenção prolongada do dente decíduo é considerada um fator local que pode retardar a irrupção do sucessor permanente, que pode ser acarretado pela diminuição metabólica do organismo. ${ }^{(9)}$ Um sinal clínico característico de proximidade do elemento dental permanente e de esfoliação do decíduo, é a mobilidade do mesmo.

Pela falta de preparação das crianças pelos pais, muitas crianças desenvolvem emoções negativas em relação ao tratamento odontológico, em que as brincadeiras, conversas e ideias estereotipadas sobre ir ao dentista estão relacionadas ao modo como as pessoas vêm tratamentos dentários. Deve-se evitar que a primeira experiência da criança com o dentista esteja ligada a dor, que requer tratamento imediato ou processos cirúrgicos. ${ }^{(10)}$

Os principais motivos causadores de medo e ansiedade na criança frente ao tratamento dentário são: em especial o fórceps ou "coisa de arrancar dente", seguido da caneta de alta rotação, da anestesia, e da cor da roupa do dentista. ${ }^{(11)}$

Desta forma, quando a criança chega ao consultório com dentes decíduos esfoliando fisiologicamente, mas os pais relatam que não conseguem auxiliar na remoção, e as crianças resistem em ajudar nesta esfoliação, os responsáveis levam para o ato cirúrgico na clínica odontológica. Buscando evitar um ato cirúrgico ou a remoção do elemento dental sem preparo psicológico infantil, existe uma técnica alternativa simples, utilizada por alguns profissionais, que poderá auxiliar na aceleração do descarte dental de dentes decíduos anteriores. $O$ objetivo deste artigo foi apresentar a técnica com fragmento de dique de borracha na esfoliação decídua de dentes anteriores e auxiliar na aceleração da remoção do dente, com a finalidade de evitar traumas psicológicos, por meio da descrição de dois casos clínicos.

\section{CASO CLÍNICO 1}

A criança do gênero feminino, com 6 anos de idade, apresentou-se ao consultório dentário com queixa de dentes amolecidos que começavam a incomodar ao mastigar, ou seja, com mobilidade fisiológica grau 3 nos incisivos centrais superiores direito e esquerdo decíduos (51 e 61). Ao realizar o preenchimento da anamnese, constatou-se que não houve traumatismo dentário e que a criança estava no período de troca dentária, segundo a cronologia de erupção. Com o exame clínico bucal e radiografia, notou-se uma boa higiene bucal e ausência de patologias como doença cárie ou periodontal. 
Os responsáveis relataram que a filha estava incomodada e eles não tinham coragem de ajudá-la com a remoção dos dentes. A criança estava com muito medo que o profissional realizasse um procedimento cirúrgico, desta forma a dentista optou por uma técnica não invasiva que permitisse acelerar a esfoliação dental. Utilizou-se um fragmento de borracha (dique de borracha) perfurado com o menor diâmetro esférico (figura 1). Este fragmento de dique foi colocado no dente com o auxílio do fio dental (figura 2), encaixando no colo cervical dentário (figura 3), em que provocou uma leve isquemia devido à pressão da borracha incidindo sobre o tecido gengival (figura 4).

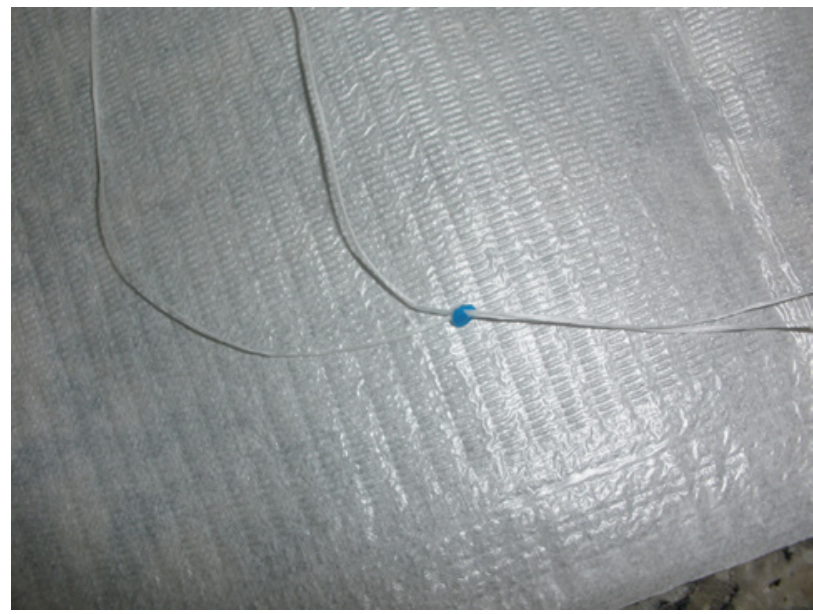

Figura 1 - Fragmento de borracha preparado com o auxílio do fio dental

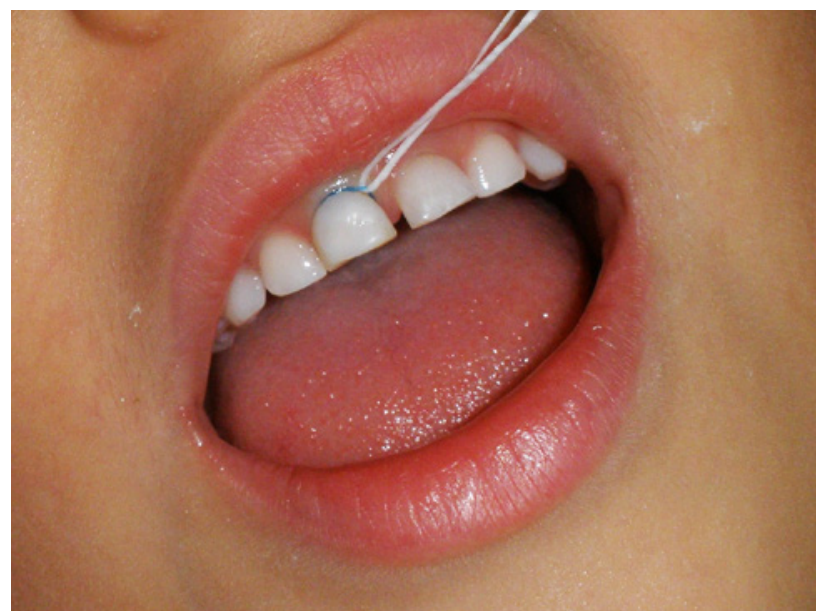

Figura 3 - Encaixe do dique na região subgengival
A profissional explicou aos responsáveis qual o objetivo da técnica e os alertou para a importância do acompanhamento nesta fase de troca dentária, com o intuito de evitar a possibilidade de deglutição ou aspiração do dente esfoliado. A figura 5 apresenta a radiografia dos elementos 51 e 61 em processo de esfoliação fisiológica.

Após dois dias, os dentes aumentaram a mobilidade e houve esfoliação natural (figura 6) sem trauma psicológico da criança. A criança relatou não ter sentido dor e estava contente com a "nova janelinha". A face incisal do dente permanente 11 (Incisivo central superior direito) já era visível clinicamente. Este procedimento foi selecionado para evitar o uso de anestésico local e ajudar o condicionamento psicológico infantil.

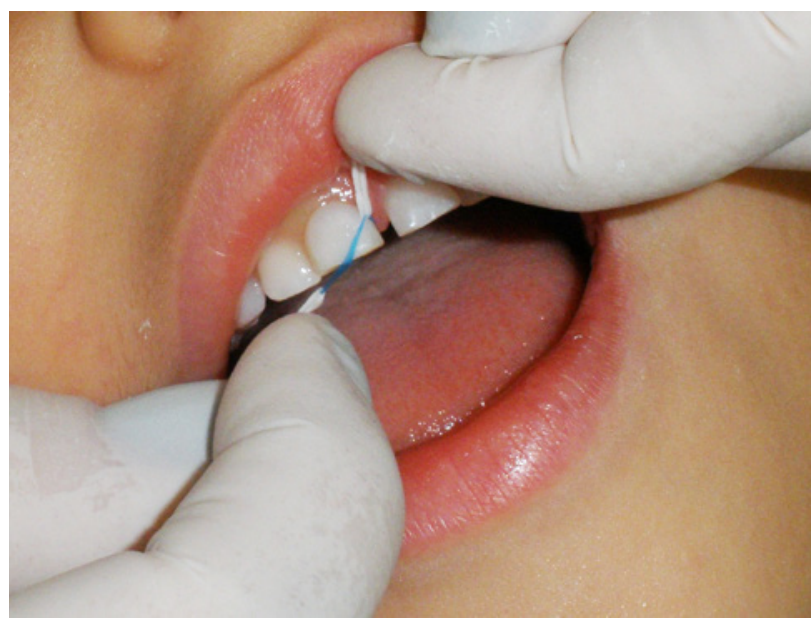

Figura 2 - Inserção do fragmento do dique de borracha para adaptar no dente

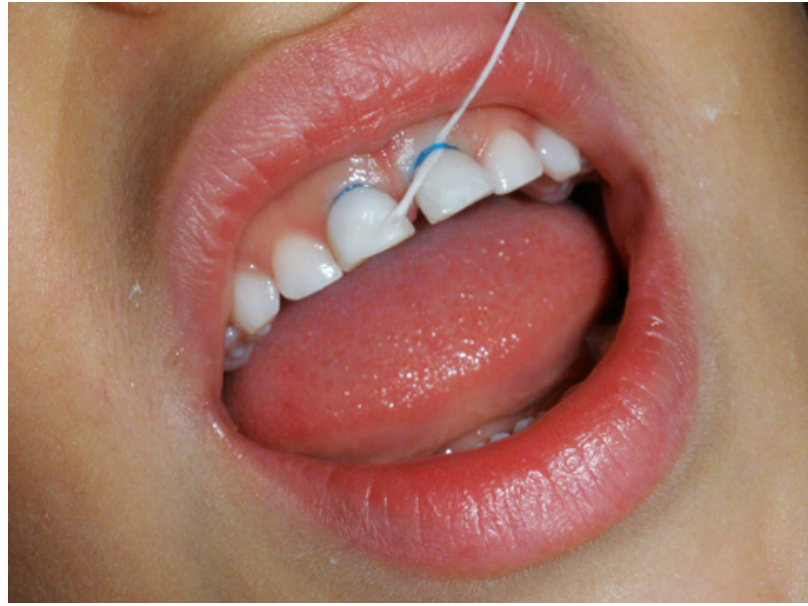

Figura 4 - Isquemia devido a leve pressão subgengival 


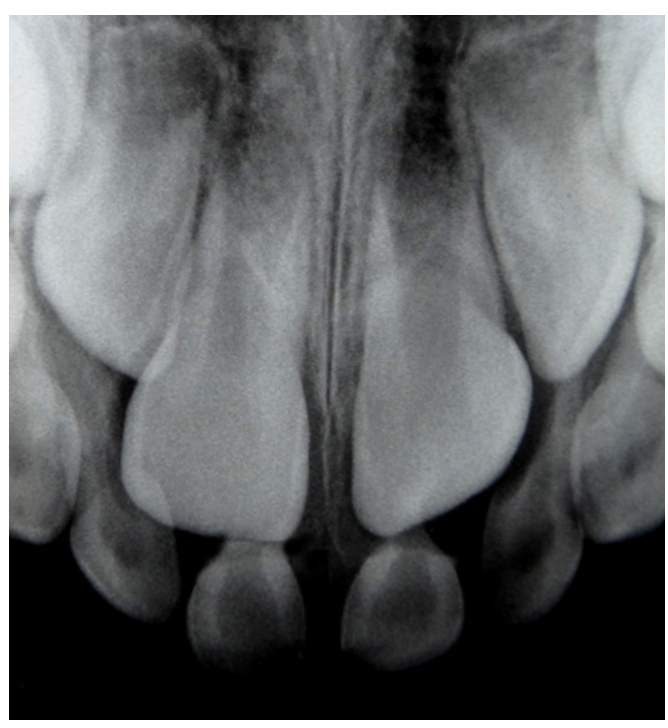

Figura 5 - Radiografia periapical com Esfoliação natural após 2 dias

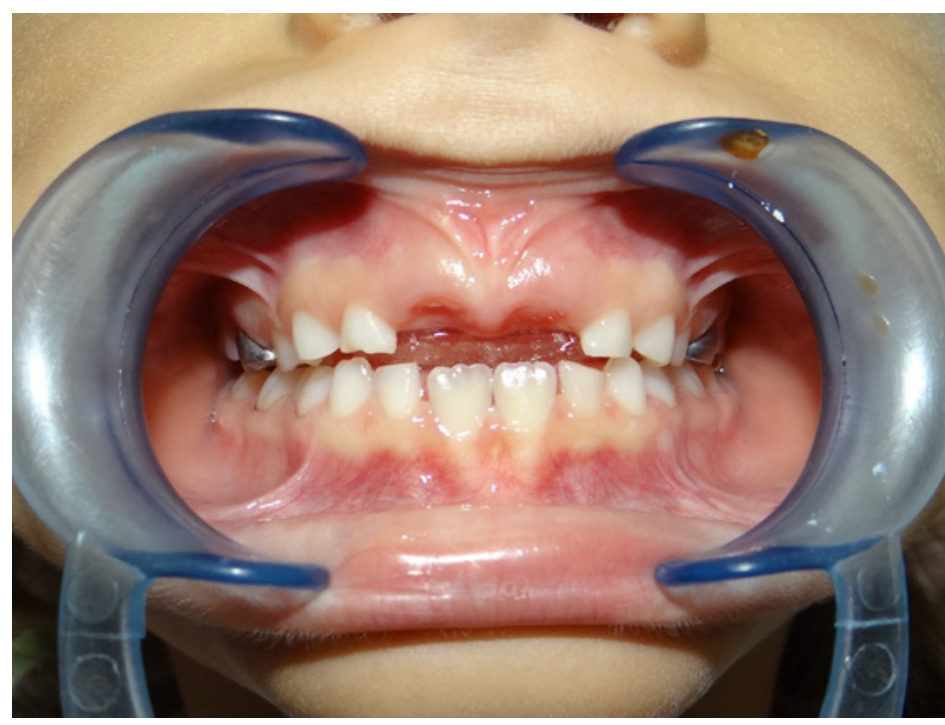

Figura 6 - Esfoliação natural após 2 dias sem reclamação da criança

\section{CASO CLÍNICO 2}

O caso 2 foi similar ao primeiro caso, pois uma criança do gênero masculino de 6 anos de idade, apresentava o dente incisivo lateral esquerdo com mobilidade e já incomodava ao mastigar, porém a mãe relatou que o filho não deixava que ela removesse o dente. Ao realizar o preenchimento da anamnese, constatou-se na história relatada que " o dentinho do lado", a mãe conseguiu retirar, mas que este dente ele não deixava a mãe encostar. $\mathrm{O}$ profissional convenceu a criança a ser examinada e prometeu não remover o dente, apenas analisar como o dente se encontrava. Ao realizar o exame clínico bucal, notou-se a presença do dente permanente 41 (incisivo central inferior direito), o paciente tinha uma boa higiene bucal e ausência de patologias como doença cárie ou periodontal. Neste mesmo dia realizou-se a tomada radiográfica para a confirmação do diagnóstico (figura 7).

Desta forma, optou-se para o uso da técnica com o dique de borracha (figura 8), em que o profissional, para tranquilizar a criança, relatou que colocaria um "cinto azul" no dente para ajudar que o dente "caísse sozinho". A criança permitiu a colocação da borracha e acompanhou todo o procedimento com a visualização por espelho. Depois de acondicionada a borracha no colo, a criança foi para casa. No outro dia, ao cair o dente, a criança trouxe o elemento dental ainda com a borracha no colo dentário (figuras 9 e 10), e relatou que achou "muito legal".

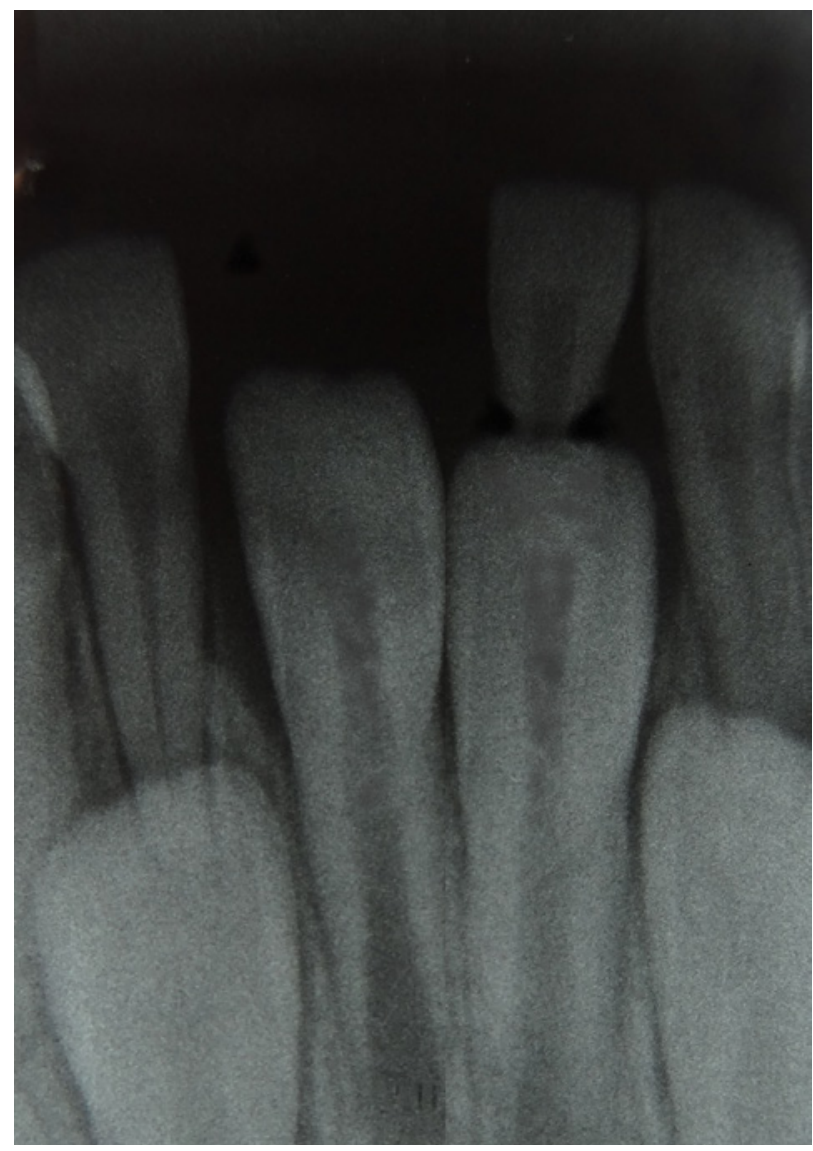

Figura 7 - Radiografia periapical com o dente 71 em rizólise fisiológica 


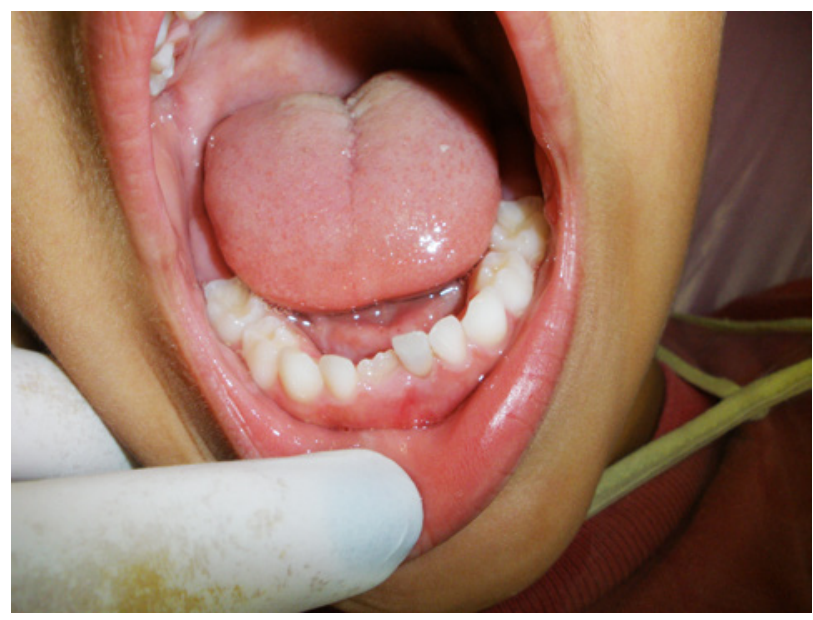

Figura 8 - Uso da técnica com dique de borracha. A criança apresentava o dente 71 com mobilidade acentuada, mas tinha medo de remover o dente

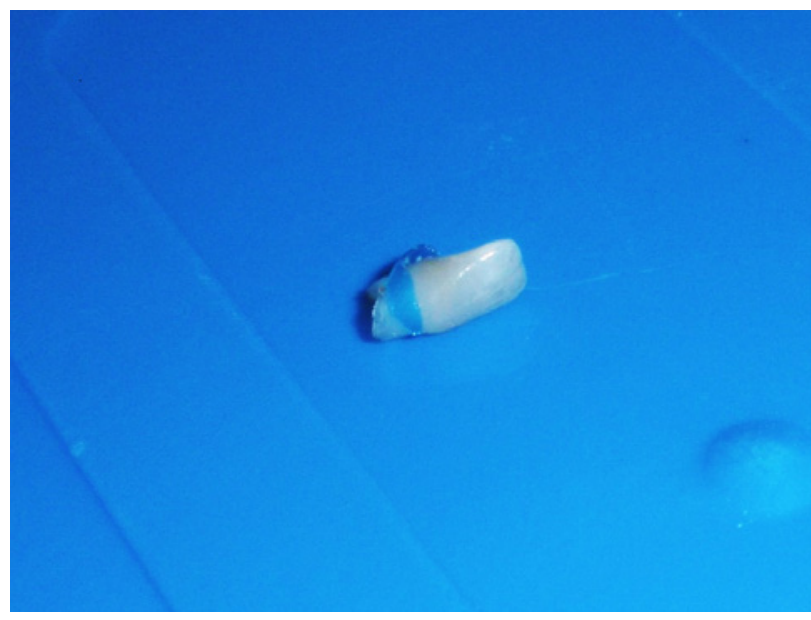

Figura 10 - Dente ainda com a borracha no colo dental

\section{DISCUSSÃO}

Esfoliação na dentadura decídua é um processo comum e desejável, onde naturalmente o dente primário amolece, cai e surge então o dente permanente. Geralmente não é preciso nenhum tipo de intervenção maior, pois as próprias crianças removem mastigando ou puxando-o. No entanto, é comum a ansiedade da troca dentária, em que muito dependerá das atitudes familiares. Majstorovic et al ${ }^{(12)}$ constataram que há influência negativa da ansiedade odontológica da mãe e da experiência médica anterior da criança, sobre a sua conduta em situações de tratamentos dentários. A influência materna é

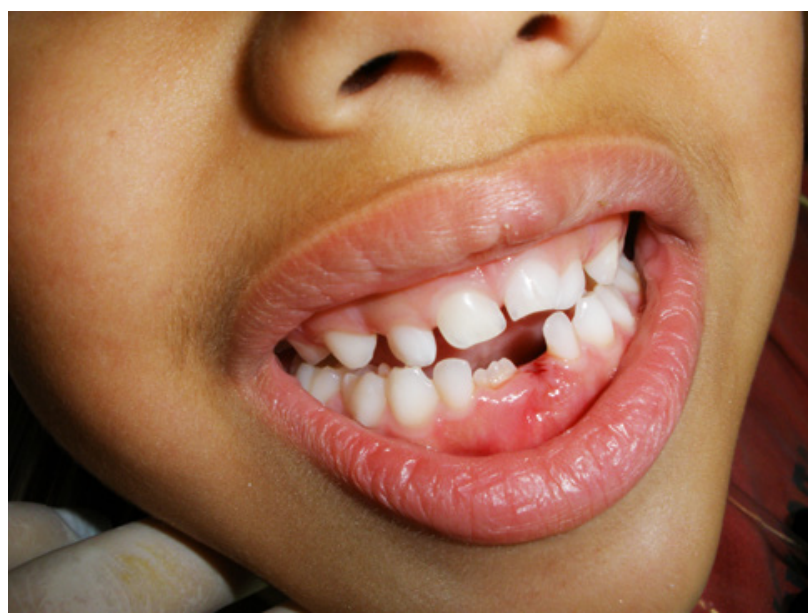

Figura 9 - Queda natural do dente após 24 horas

importante no atendimento odontológico da criança, e segundo Trieger e Bernstein, ${ }^{(11)}$ quando a mãe tem experiências passadas negativas em relação ao dentista, esta não é hábil a consolar o filho sobre o tratamento ser agradável. Crianças cujas mães tiveram experiências odontológicas agradáveis no passado tendem a ser mais cooperativas ao tratamento.

O nível de medo e ansiedade em relação ao tratamento dentário é maior nas meninas que nos meninos, o medo prevalece mais entre os maiores, e a idade não influência o nível de ansiedade. ${ }^{(13)} \mathrm{Em}$ contrapartida, Reis et al(14) constataram que a maioria das crianças que apresentam boa conduta são os com idade acima de 9 anos, sugerindo que as crianças que demonstram conduta negativa durante a consulta são as mais novas. Nos casos clínicos apresentados neste estudo elas tinham 6 anos.

O tipo de procedimento influencia tanto no comportamento da criança, como também à conduta do cirurgião-dentista. Vários são os procedimentos que mais provocam ansiedade em relação ao tratamento dentário como: o ato da anestesia local, a espera prolongada pelo atendimento, a exodontia e a raspagem periodontal. ${ }^{(10)}$ No entanto para Ribas et al, ${ }^{(15)}$ não há diferença relacionada a ansiedade na criança e os tipos de procedimentos a que são submetidas com ou sem anestesia local, ou seja, entre os tratamentos mais invasivos e os preventivos. 
A anestesia local é um dos principais fatores causadores de dor e de ansiedade. Nos casos clínicos relatados neste estudo, as crianças se encontravam com dentes decíduos em processo de esfoliação natural, mas os pais não tinham coragem de ajudá-las a removê-los. As crianças apresentavam muito medo do ato cirúrgico, assim, o tratamento de escolha foi a técnica com fragmento de borracha o que dispensou a aplicação de anestesia local. Fato comprovado por Trieger e Bernstein ${ }^{(11)}$ que afirmam que as exodontias produzem tensões marcantes na criança e exigem compreensão e especial atenção aos sentimentos da criança durante o procedimento.

A maior preocupação dos pais que procuraram nos casos clínicos apresentados neste estudo, era o "medo do dente de leite não cair e prejudicar o dente permanente que iria nascer". Os dentes decíduos com mobilidade fisiológica devem esfoliar, pois a retenção prolongada do dente primário pode retardar a irrupção do sucessor permanente e promover distúrbios oclusais. ${ }^{(6)}$

A apoptose é o mecanismo pelo qual desaparecem dos maxilares as células da polpa e do periodonto dos dentes decíduos, expondo porém, em um primeiro momento, as superfícies interna e externa dos tecidos mineralizados dos dentes. Na reabsorção fisiológica dental, é importante manter continuamente estímulos que advêm dos mediadores presentes e de estresse tecidual. (4) Assim, acredita-se que a técnica de colocação do fragmento perfurado do dique de borracha, quando inserida no colo do dente, provoca compressão na região subgengival promovendo estímulo a apoptose das fibras gengivais remanescentes dentárias locais, favorecendo a liberação do elemento dental.

Esta técnica auxiliar tem sido usada com frequência em consultórios de odontopediatria, em que os profissionais a realizam ao encontrarem a indicação clínica apresentada nos relatos descritos, para que esta criança, com acentuado medo e ansiedade ao procedimento cirúrgico, possa colaborar e perceber $\mathrm{o}$ atendimento odontológico de forma mais agradável e motivadora. No entanto, não foram encontrados estudos na literatura que possam embasar cientificamente esta técnica. Mesmo assim, estes autores se propuseram a descrever esta alternativa empírica ${ }^{(16)}$ para lançar o desafio de novos estudos e verificação de sua real eficácia. A técnica apresentada parece ser uma boa alternativa para auxiliar a esfoliação fisiológica de dentes decíduos anteriores em crianças ansiosas e com medo.

\section{CONCLUSÃO}

Considerando a literatura consultada e os casos clínicos expostos, é lícito concluir que a melhor conduta para decíduos em esfoliação natural é que a própria criança consiga remover seus próprios dentes. No entanto, se a criança não conseguir remover sozinha, ou com o auxílio dos pais, o profissional precisa intervir para que este dente não incomode a criança, ou venha a dificultar a irrupção dentária do sucessor permanente.

O cirurgião-dentista pode optar por um ato cirúrgico ou técnicas alternativas. No entanto, deve-se lembrar que o ato cirúrgico parece ser um dos procedimentos que mais gera medo e ansiedade nas crianças em relação ao tratamento dentário. Por isso, a técnica com fragmento de dique de borracha para auxiliar na esfoliação fisiológica e permitir a queda do dente anterior, pode ser uma das indicações para ajudar crianças medrosas e ansiosas, evitando traumas psicológicos. Tornam-se necessários estudos e pesquisas para melhor avaliar esta técnica.

\section{REFERÊNCIAS}

1. Yang J, Zhao YM, Ge LH. Establishment of permanent tooth germ missing animal model and study on root resorpti on of the corresponding deciduous teeth. Beijing Da Xue Xue Bao. 2008; 40(1):60-3.

2. Lourenço SQC, Consolaro A. Apoptosis in odontogenesis: dental lamina, Hertwig's epithelial sheath and reduced ameloblasts. J Dental Res. 1997;76:120. 
3. Frajndlich SB, Oliveira FAM. Fatores que afetam a erupção dentária infantil. Rev. Odonto Ciênc. 1988;6:7-12.

4. Consolaro A. Dentes decíduos remanescentes em adultos e sua rizólise: implicações e aplicações clínicas. Rev Clín Ortodon Dental Press. 2007;6(2):108-11.

5. Rossi A, Rossi M. Mecanismos celulares e moleculares envolvidos na reabsorção radicular de dentes decíduos. Pesqui Bras Odontopediatria Clin Integr. 2010;1O(3):505-11.

6. Valentine FF, Carvalho PL, Candelária LFA. Estudo dos fatores que alteram a cronologia de erupção dentária. SOTAU Rev Virtual Odontol. 2007;3(1):18-23.

7. Domon T, Taniguchi Y, Inove K, Ushijima N, Taishi Y, Hiramatsu A et al. Apoptosis of odontoclasts under physiological root resorpti on of human deciduous teeth. Cell Tissue Res. 2008;331(2):423-33.

8. Santos BZ, Bosco VL, Silva JYB, Cordeiro MMR. Mecanismos e fatores fisiológicos e patológicos no processo de reabsorção radicular de dentes decíduos. RSBO. 2010;7(3):332-9.

9. Crispim ASS, Duarte DA, Bonecker M. Manifestações locais e sistêmicas durante a erupção dentária decidua. Rev Odontol Univ St Amaro. 1997;2(3):8-11.
10. Alsarheeda M. Children's perception of their dentists. Euro J Dent. 2011;5:186-90.

11. Trieger N, Bernstein NR. Good child, bad tooth: management of the fear of tooth extraction in children. Oral Surg Oral Med Oral Pathol. 1963;16(3):261-70.

12. Majstorovic M, Skrinjaric I, Glavina D, Szirovicza L. Factors predicting a child's dental fear. Coll Antropol. 2001;25(2):493-500.

13. Singh KA, Moraes ABA, Ambrosano GMB. Medo, ansiedade e controle relacionados ao tratamento odontológico. Pesqui Odontol Bras. 2000;14(2):131-6.

14. Reis F, Dias MR, Leal I. A consulta no setting odontopediátrico: a percepção subjetiva do medo. Anál Psicol. 2008;2(XXVI): 239-50.

15. Ribas TA, Guimarães VP, Losso EM. Avaliação da ansiedade odontológica de crianças submetidas ao tratamento odontológico. Arq Odontol. 2006;12(3):190-8.

16. Rank RCIC, Aguiar KRS, Marquez L, Vilela JER. Técnica auxiliar na esfoliação de dentes decíduos: relato de casos (C21). In: Anais do $24^{\circ}$ Congresso Brasileiro de Odontopediatria; $2 \mathrm{Ol3}$ out 25-27; Brasília, Brasil. João Pessoa: UFPB; 2013. 